\title{
Effects of nutrition, depression symptoms and demographic characteristics on dementia in the elderly population
}

\author{
Sadik TASER (D), Ruhusen KUTLU (D), Nazan KARAOGLU (D)
}

Department of Family Medicine, Meram Medical Faculty, Necmettin Erbakan University, Konya, Turkey.

\author{
Corresponding Author: Ruhusen KUTLU
}

E-mail: ruhuse@yahoo.com

Submitted: 11.01.2021 Accepted: 20.03.2021

\begin{abstract}
Objective: Due to the increase in the elderly population, there is an increase in chronic diseases, infections, depression, and nutritional problems as well as a decrease in cognitive abilities. This study aimed to investigate the effects of nutritional status, depression symptoms and demographic characteristics on dementia in the elderly population.

Materials and Methods: This study is a cross-sectional analytic study which took place between first day of April to first day of June in 2018 in three family health centers selected by simple random sampling from random numbers table in Konya, Turkey. Mini Nutritional Assessment normal (MNA) and short form (MNA-SF), Geriatric Depression Scale-30 (GDS-30) and the Standardized Mini-Mental Test (SMMT) was applied to 298 elderly people.

Results: Mild dementia was found in $11.4 \%(n=34)$ and, depression symptoms were detected in $5.7 \%(n=17)$ of total. MNA-SF showed that $15.8 \%$ were under the risk of malnutrition while $2.3 \%$ had malnutrition. MNA-SF total score ( $\mathrm{p}=0.004)$ was significantly higher in males than in females showing that there was more cognitive impairment in women than men. There was a significant relationship between the presence of dementia and gender $(\mathrm{p}=0.048)$, age groups $(\mathrm{p}=0.006)$, education $(\mathrm{p}<0.001)$, MNA-SF $(\mathrm{p}=0.012)$ and MNA ( $\mathrm{p}=0.002)$. Conclusion: The frequency of dementia was higher in women, in low educated, depressive and aged ones and in those with malnutrition. Regarding dementia, depression and malnutrition in the elderly in primary care; it is important to use well designed specific scales to these conditions for early diagnosis.

Keywords: Nutrition, Depression symptoms, Standard Mini-Mental Test, Elderly
\end{abstract}

\section{INTRODUCTION}

Aging is an inevitable and irreversible process that is easily identifiable and associated with structural and functional changes in the individual organism. Ageing is the primary risk factor for most neurodegenerative diseases, including Alzheimer's disease $(\mathrm{AD})$ and Parkinson's disease (PD). One in ten individuals aged $\geq 65$ years has $\mathrm{AD}$ and its prevalence increases with increasing age [1]. The ageing-related neurodegenerative diseases are associated with large socioeconomic and personal costs. Being elder is defined as 65 years of age by the World Health Organization (WHO) [2]. Although, elderly population was $4.2 \%$ in 1985, it increased to $7.7 \%$ in 2013 and to $8.5 \%$ in 2017, in Turkey [3].

The incidence of chronic diseases and cancers increases with old age and cognitive abilities frequently decrease. During this period, psychological problems, care problems resulting in skipping meals and poor diet are common and all these factors cause malnutrition. Malnutrition, on the other hand, increases mortality risk via deterioration in normal physiological functions, decrease in bone mass, impairment in immune system, delays in post-operative recovery and prolonged hospital stay [ 4].

The term 'dementia', called senility in daily life, is a word derived from 'mens' which means mind in Latin in origin and it means the loss of the established, existing, acquired mind with the negative suffix [5]. Dementia is a neurodegenerative disorder in which psychiatric and behavioral symptoms are seen together and characterized by a progressive deterioration in memory and other cognitive functions, a loss in acquired social and intellectual skills which influence daily life $[2,5]$. Elderly depression is accepted as an increasing public health problem worldwide. The importance of depression lies in the acceptance of depressive symptoms and cognitive loss as a normal ageing process, and the elderly generally declare the signs as an expected outcome of ageing. So, specific attention while taking patient history, and specific questions to identify depression are needed $[6,7]$.

How to cite this article: Taser S, Kutlu R, Karaoglu N. Effects of nutrition, depression symptoms and demographic characteristics on dementia in the elderly population. Marmara Med J 2021; 34(2):132-139. doi: 10.5472/marumj.939806 
It is difficult to diagnose dementia at an early stage because by getting older, forgetfulness is accepted as a normal process of ageing. The most commonly used clinical test for the evaluation of dementia is Standardized Mini Mental Test (SMMT). By reason of mimicking cognitive impairment, screening for depression is important. In addition to SMMT, Geriatric Depression Scale (GDS) should be performed to make a differential diagnosis for depression $[1,2,8]$.

This study aimed to investigate the effects of nutritional status, depression and demographic characteristics on dementia in individuals aged 65 years and older who applied to family health centers (FHC) in Konya.

\section{MATERIALS and METHODS}

\section{The type, place and population of the study}

This study is a cross-sectional analytic study which took place between first day of April to first day of June in 2018 in three family health centers selected by simple random sampling from random numbers table in Konya. During this period, 298 individuals aged 65 years and over who applied to the family health center for general check-up and accepted to participate were included in the study.

In a previous study, the prevalence of dementia in individuals over the age of 65 in our country was found to be $8.4 \%$ [6]. Since, the number of individuals in the universe was unknown in our study, the number of subjects required to be included in the study was calculated using the formula " $\mathrm{n}=\mathrm{t}^{2} . \mathrm{p} . \mathrm{q} / \mathrm{d}^{2}$." Accordingly, the study was completed with 298 individuals.

\section{Exclusion criteria}

Those who refused to participate, who were not able to answer the questions, those who had been diagnosed with dementia before and had been diagnosed with severe psychiatric disease and those whose native language was not Turkish were not included in the study.

\section{Ethical authorization of the study}

Ethics committee approval was received before starting the study (Approval number: 2017/1054 Date:03.11.2017). The participants were informed about the study and their written and verbal consent was obtained according to the principles of Helsinki Declaration.

\section{Collecting the data}

Sociodemographic variables of the participants were recorded The questionnaires used had three main parts: 1-Standardized Mini-Mental Test (SMMT), 2-Normal and short form of Mini Nutritional Assessment (MNA) test, 3-Geriatric Depression Scale-30 (GDS-30).

\section{Sociodemographic Variables}

The sociodemographic questionnaire included age, gender, marital status, occupation, education, place of residence, family structure, and economic status. Smoking, alcohol use and the existence of chronic diseases were also questioned. The researcher filled in the questionnaire using face to face interview method.

\section{Standardized Mini Mental Test (SMMT)}

Standardized Mini Mental Test, which provides assessment of cognitive status, was developed by Folstein et al. in 1975 and it is the most common and easy test for dementia screening [8]. The validity and reliability study of the test in the diagnosis of mild dementia for the Turkish population was performed by Güngen et al [9]. Standardized Mini-Mental Test was grouped under five headings: orientation (10 points), record memory ( 3 points), attention and calculation (5 points), recall ( 3 points) and language (9 points). The total score of the scale is 30 points and it has two different types for the educated and uneducated. Generally, the scores between 24 and 30 are accepted as normal. A score below 24 indicates cognitive impairment, a score between 18-23 shows mild dementia, a score between 12-17 means moderate dementia and a score below 12 is noted as severe dementia [9].

In the present study, the minimum SMMT score was 19 points, and there was no participant with moderate or severe dementia. Therefore, those with SMMT total score between 24 and 30 were considered as the normal group and under 24 points as the cognitively impaired (dementia group). Two different MMSE forms for educated and uneducated individuals were applied.

\section{Mini Nutritional Assessment (MNA)}

Recently, MNA has been widely used in the assessment of nutritional status. It was developed in 1994 in collaboration with the University of Toulouse, Medical Faculty of New Mexico and Nestle Research Center of Switzerland [10]. Following MNA, MNA-SF was developed and validated in 2001 by Rubenstein et al [11]. The validity study of MNA and MNA-SF forms in geriatric patients in Turkey was studied by Sarikaya [12].

Mini Nutritional Assessment starts with six screening questions (questions A-F1/F2), which are a maximum of fourteenpoint MNA-Short form (MNA-SF). If eleven or less points are obtained as a result of this questioning, it is recommended to continue the other questions (questions G-S). This will the final MNA score: Under 17 points means malnutrition, 17-23.5 points means there is a risk of malnutrition and $>23.5$ points indicates adequate nutrition [13].

\section{Geriatric Depression Scale (GDS)}

This scale was developed by Yesavage, et al., in 1983 for screening depression in elderly patients based on self-report [14]. The reliability and validity study of the scale was performed by Ertan, Eker and Sar in 1997 [15]. It has 30 'yes or no.' questions which the elderly can easily answer. While scoring the scale, 1 point is given for each response in favor of depression and 0 points is given for the other response, and as a result, it is accepted as total depression score. The scoring of the scale was arranged as 0-10 points no depression, 11-13 points possible depression, 14 and above points definite depression. The scores obtained from the scale are minimum:0, maximum:30 [15]. 


\section{Anthropometric Measurements}

Height measurements required for the calculation of body mass index (BMI) were performed without shoes with a tape measure attached to the wall while looking ahead in the most upright position possible. Body weight was determined with a digital scale sensitive to 100 grams while looking ahead in the upright position without shoes. BMI was calculated by dividing body weight (in kilograms) by the square of the height (in meters). For the measurement of mid upper arm circumference, the arm was bent to $90^{\circ}$ and the point between the acromial protrusion on the shoulder and olecranon protrusion on the elbow was marked and the circumference of the arm from this point was measured and recorded as centimeters. For calf circumference measurement, while the person was lying on his back, the leg was bent to $90^{\circ}$ from the knee, the largest calf circumference was measured and the obtained value was recorded in centimeters.

\section{Skin Fold Thickness}

It provides a rough measurement of subcutaneous adipose tissue, hence fat storage and lean muscle mass. In this study, skin fold thicknesses of triceps and abdominal region were measured. Measurement of the abdominal region was performed vertically on the two $\mathrm{cm}$ right side of the umbilicus. Triceps measurements were performed vertically from the midpoint of the distance between the acromion and olecranon with the arm released near the body. While the measurements were made, the caliper was placed just above the skin fold, held with two fingers and the skin fold continued to be held with the fingers during the measurement. All measurements were performed by the same person with the same skin fold caliper.

\section{Statistical Analysis}

The data of the study were analyzed by Statistical Package for Social Sciences (SPSS) for Windows 20.0. Before comparing the educational status and dementia status of the participants, the educational status was divided into two groups as 'illiterate' and 'primary and higher education' taking into account the number in each group. Before comparing the nutritional status of the participants according to MNA, MNA-SF and dementia status, taking into account the numbers in each group again, the nutritional status according to MNA and MNA-SF was divided into two groups as 'malnutrition and risk of malnutrition' and 'normal nutritional status'. Before statistical evaluation, the economic status and dementia of the participants, taking into account the numbers in each group, the economic status was divided into two groups as 'less income than expenses' and 'equal or more income than expenses'. Descriptive statistics of continuous variables were summarized in terms of mean and standard deviation, and descriptive statistics of categorical data were summarized in terms of frequency and percentage in tabular form. In the comparison of quantitative data, independent t-test was used in paired groups that met the normal distribution assumption, and One-Way ANOVA test and Post Hoc test were used for three or more groups. Chisquare test was used to compare categorical data. Results were evaluated at 95 percent confidence interval and significance was at $\mathrm{p}<0.05$ level. Pearson correlation analysis was used for correlations between parameters. Correlation coefficient ( $r$ ) was evaluated as weak between $0.00-0.24$, moderate between 0.25 0.49 , strong between $0.50-0.74$, very strong between $0.75-1.0$.

\section{RESULTS}

A total of 298 data of the participants who met the inclusion criteria were analyzed. The mean age of the study group was $72.1 \pm 5.7$ years and most of them $(71.5 \% ; n=213)$ were $64-74$ years of age. The $52.7 \%(n=157)$ were male, $74.5 \%(n=222)$ were married, 67.4\% $(n=201)$ had nuclear families and 55.7\% $(n=166)$ were graduated from primary school.

According to the results of the SMMT; $88.6 \%(n=264)$ of the elderly were at normal level and $11.4 \%(n=34)$ had cognitive impairment (dementia). GDS scores of participants showed that the prevalence of depression was $5.7 \%(n=17)$. The median score of SMMT was $27.0(\min =19.9, \max =30.0)$. The median score of GDS was 2.0 $(\min =0.0, \max =21.0)$. The risk of malnutrition was $15.8 \%(n=47)$ and $2.3 \%(n=7)$ had malnutrition according to MNA-SF. MNA long form was applied to 54 people with 11 points and below in MNA-SF. This time $14.4 \%(n=43)$ were at risk of malnutrition and $1.0 \%(n=3)$ had malnutrition according to MNA.

Body mass index values of the participants showed that $45 \%$ $(n=134)$ of them were overweight and $37.9 \%(n=113)$ were obese. Multidimensional geriatric assessment tests and the distribution of BMI were shown in Table I.

The participants were compared in respect to gender, age, educational and economic status and dementia scores. A significant relationship was found between dementia and gender $(p=0.048)$, age groups $(p=0.006)$, educational status $(\mathrm{p}<0.001)$. The prevalence of dementia was higher in the 75 -year-old group, the illiterate ones and in female gender. The incidence of dementia was lower in educated ones. When the relationship between gender and dementia of the participants was examined, there was no relationship between dementia and education in male gender $(\mathrm{p}=0.277)$, whereas dementia was less common in educated women $(\mathrm{p}=0.005)$. The comparison of sociodemographic characteristics and SMMT scores of the participants is shown in Table II.

A significant relationship was found between the dementia scores of the participants and GDS-30 ( $\mathrm{p}<0.001)$, MNA-SF $(\mathrm{p}=0.012)$, MNA ( $\mathrm{p}=0.002)$ and those with dementia according to SMMT, but no relationship was found between BMI $(\mathrm{p}=0.820)$ and dementia (Table III). The dementia percentage was higher in those with malnutrition and at risk of malnutrition according to MNA-SF and MNA, than in those in normal nutritional status.

While $47.1 \% \quad(n=8)$ of the participants with depression according to GDS-30 had dementia, 9.3\% $(n=26)$ of those without depression had dementia. The prevalence of dementia was higher in patients with depression according to GDS-30 than those without depression. The comparison of the dementia status of the participants to GDS-30, MNA-SF, MNA and BMI is shown in Table III. 
Table I. Multidimensional geriatric assessment tests and distribution of $B M I$

\begin{tabular}{|l|c|c|}
\hline Parameters & n & $\%$ \\
\hline SMMT & & \\
\hline Normal (Between 24 - 30 points) & 264 & 88.6 \\
\hline Mild dementia (Between18-23 points) & 34 & 11.4 \\
\hline GDS-30 & 281 & 94.3 \\
\hline No depression (Between 0-10 points) & 17 & 5.7 \\
\hline Depression (Between 11-30 points) & & \\
\hline MNA-SF & 7 & 2.3 \\
\hline Malnutrition between 0-7 points & 47 & 15.8 \\
\hline At the risk of Malnutrition between 8-11 points & 244 & 81.9 \\
\hline Normal nutrition between12-14 points & & \\
\hline MNA & 3 & 1.0 \\
\hline Malnutrition below17 points & 43 & 14.4 \\
\hline Risk of malnutrition between $17-23.5$ points & 252 & 84.6 \\
\hline Normal nutrition between $24-30$ points & & \\
\hline BMI & 2 & 0.7 \\
\hline BMI weak (below $18.5 \mathrm{~kg} / \mathrm{m}^{2}$ ) & 49 & 16.4 \\
\hline BMI normal weight between $18,5-24,99 \mathrm{~kg} / \mathrm{m}^{2}$ & 134 & 45.0 \\
\hline BMI overweight between $25-29,99 \mathrm{~kg} / \mathrm{m}^{2}$ & 113 & 37.9 \\
\hline BMI obese $30 \mathrm{~kg} / \mathrm{m}^{2}$ and over & 298 & 100.0 \\
\hline Total & & \\
\hline
\end{tabular}

SMMT: Standardized Mini-Mental Test, GDS-30: Geriatric Depression Scale Long Form, MNA: Mini Nutritional Assessment, MNA-SF: Mini Nutritional Assessment Short Form, BMI: Body Mass Index

Table II. Comparison of sociodemographic characteristics and SMMT results

\begin{tabular}{|c|c|c|c|c|c|c|}
\hline \multirow[t]{3}{*}{ Parameters } & \multicolumn{4}{|c|}{ SMMT } & \multirow[b]{3}{*}{$x^{2}$} & \multirow[b]{3}{*}{ p } \\
\hline & \multicolumn{2}{|c|}{ Dementia } & \multicolumn{2}{|c|}{$\begin{array}{c}\text { No } \\
\text { dementia }\end{array}$} & & \\
\hline & $\mathbf{n}$ & $\%$ & $\mathrm{n}$ & $\%$ & & \\
\hline \multicolumn{7}{|l|}{ Gender } \\
\hline Male & 12 & 7.6 & 145 & 92.4 & \multirow[t]{2}{*}{3.902} & \multirow[t]{2}{*}{0.048} \\
\hline Female & 22 & 15.6 & 119 & 84.4 & & \\
\hline \multicolumn{7}{|l|}{ Age groups } \\
\hline Between 65-74 years of age & 17 & 8.0 & 196 & 92.0 & \multirow[t]{2}{*}{7.534} & \multirow[t]{2}{*}{0.006} \\
\hline$\geq 75$ years of age & 17 & 20.0 & 68 & 80.0 & & \\
\hline \multicolumn{7}{|l|}{ Educational Status } \\
\hline Illiterate & 19 & 24.1 & 60 & 75.9 & \multirow[t]{2}{*}{15.336} & \multirow[t]{2}{*}{$<0.001$} \\
\hline Primary and higher education & 15 & 6.8 & 204 & 93.2 & & \\
\hline \multicolumn{7}{|l|}{ Education in males $(n=12)$} \\
\hline Illiterate & 2 & 16.7 & 10 & 83.3 & \multirow[t]{2}{*}{1.180} & \multirow[t]{2}{*}{0.277} \\
\hline Primary and higher education & 10 & 6.9 & 135 & 93.1 & & \\
\hline \multicolumn{7}{|l|}{ Education in females $(n=22)$} \\
\hline Illiterate & 17 & 25.4 & 50 & 74.6 & \multirow[t]{2}{*}{7.895} & \multirow[t]{2}{*}{0.005} \\
\hline Primary and higher education & 5 & 6.8 & 69 & 93.2 & & \\
\hline \multicolumn{7}{|l|}{ Economical situation } \\
\hline Less income than expenses & 9 & 18.8 & 39 & 81.2 & \multirow[t]{2}{*}{2.246} & \multirow[t]{2}{*}{0.134} \\
\hline $\begin{array}{l}\text { Equal or more income than } \\
\text { expenses }\end{array}$ & 25 & 10.0 & 225 & 90.0 & & \\
\hline Total & 34 & 100.0 & 264 & 100.0 & & \\
\hline
\end{tabular}

SMMT: Standardized Mini-Mental Test. ${ }^{*}$ Chi-square test was used for analysis
Table III. Comparison of SMMT with GDS-30, MNA-SF, MNA and BMI

\begin{tabular}{|c|c|c|c|c|c|c|}
\hline & \multicolumn{4}{|c|}{ SMMT } & \multirow[b]{3}{*}{$\chi^{2}$} & \multirow[b]{3}{*}{$\mathrm{p}^{*}$} \\
\hline & \multicolumn{2}{|c|}{ Dementia } & \multicolumn{2}{|c|}{$\begin{array}{c}\text { No } \\
\text { dementia }\end{array}$} & & \\
\hline & $\mathrm{n}$ & $\%$ & $\mathrm{n}$ & $\%$ & & \\
\hline \multicolumn{7}{|l|}{ GDS-30 } \\
\hline Depression & 8 & 47.1 & 9 & 52.9 & \multirow[t]{2}{*}{14.776} & \multirow[t]{2}{*}{$<0.001$} \\
\hline No depression & 26 & 9.3 & 255 & 90.7 & & \\
\hline \multicolumn{7}{|l|}{ MNA-SF } \\
\hline $\begin{array}{l}\text { Malnutrition / malnutrition } \\
\text { risk }\end{array}$ & 12 & 22.2 & 42 & 77.8 & \multirow{2}{*}{6.378} & \multirow{2}{*}{0.012} \\
\hline Normal nutrition & 22 & 9.0 & 222 & 91.0 & & \\
\hline \multicolumn{7}{|l|}{ MNA } \\
\hline $\begin{array}{l}\text { Malnutrition / malnutrition } \\
\text { risk }\end{array}$ & 12 & 26.1 & 34 & 73.9 & \multirow{2}{*}{9.940} & \multirow{2}{*}{0.002} \\
\hline Normal nutrition & 22 & 8.7 & 230 & 91.3 & & \\
\hline \multicolumn{7}{|l|}{ BMI } \\
\hline Obese & 14 & 12.4 & 99 & 87.6 & \multirow[t]{2}{*}{0.052} & \multirow[t]{2}{*}{0.820} \\
\hline Non-obese & 20 & 10.8 & 165 & 89.2 & & \\
\hline Total & 34 & 100.0 & 264 & 100.0 & & \\
\hline
\end{tabular}

SMMT: Standardized Mini Mental Test, GDS-30: Geriatric Depression Scale Long Form, MNA-SF: Mini-Nutritional Assessment Short Form, MNA: Mini-Nutritional Assessment, BMI: Body mass ndex. * Chi-square test was used for analysis

When the SMMT subcomponents were compared according to the gender of the participants, a significant relationship was found between the orientations $(\mathrm{p}<0.001)$, language $(\mathrm{p}<0.001)$ and the genders. The mean scores of orientation and language were higher in men than the mean scores of orientation and language in women. When the SMMT subcomponents of the participants were compared according to age groups, the mean scores of attention-calculation $(\mathrm{p}=0.041)$ and recall and language $(\mathrm{p}<0.001)$ were higher in individuals below 75 years of age compared to individuals older than 75 years (Table IV).

Table IV. Comparison of SMMT subcomponents in terms of gender and age

\begin{tabular}{|c|c|c|c|c|}
\hline \multirow{2}{*}{ SMMT subcomponents } & Male & Female & \multirow{2}{*}{$\mathbf{t}$} & \multirow{2}{*}{$\mathrm{p}^{*}$} \\
\hline & Mean \pm SD & Mean \pm SD & & \\
\hline Orientation & $9.8 \pm 0.6$ & $8.9 \pm 1.1$ & 8.109 & $<0.001$ \\
\hline Record memory & $2.9 \pm 1.1$ & $2.9 \pm 1.2$ & 0.482 & 0.630 \\
\hline Attention-calculation & $4.4 \pm 1.2$ & $4.5 \pm 1.1$ & -0.501 & 0.617 \\
\hline Recall & $1.1 \pm 1.3$ & $1.1 \pm 1.0$ & -0.023 & 0.982 \\
\hline Language & $8.6 \pm 0.5$ & $8.4 \pm 0.6$ & 4.014 & $<0.001$ \\
\hline SMMT total score & $26.8 \pm 2.0$ & $25.8 \pm 2.2$ & 3.975 & $<0.001$ \\
\hline \multirow[b]{2}{*}{ SMMT Subcomponents } & $\begin{array}{c}\text { 65-74 years } \\
\text { of age }\end{array}$ & $\begin{array}{c}\geq 75 \text { years } \\
\text { of age }\end{array}$ & \multirow[b]{2}{*}{$\mathbf{t}$} & \multirow[b]{2}{*}{$\mathrm{p}^{*}$} \\
\hline & Mean \pm SD & Mean \pm SD & & \\
\hline Orientation & $9.3 \pm 0.9$ & $9.2 \pm 0.9$ & 1.187 & 0.236 \\
\hline Record memory & $2.9 \pm 0.1$ & $2.9 \pm 0.2$ & 1.325 & 0.186 \\
\hline Attention-calculation & $4.5 \pm 0.9$ & $4.2 \pm 1.3$ & 2.057 & 0.041 \\
\hline Recall & $1.2 \pm 1.2$ & $0.7 \pm 0.9$ & 3.472 & $<0.001$ \\
\hline Language & $8.6 \pm 0.5$ & $8.2 \pm 0.6$ & 4.631 & $<0.001$ \\
\hline SMMT total score & $26.7 \pm 1.9$ & $25.5 \pm 2.3$ & 4.463 & $<0.001$ \\
\hline
\end{tabular}

SMMT: Standardized Mini Mental Test. ${ }^{*}$ Independent samples $t$-test was used for analysis 
When multidimensional geriatric assessment tests compared gender, the total score of SMMT in male $(\mathrm{p}<0.001)$ was significantly higher than in the female gender. The total score of GDS-30 $(p<0.001)$ was significantly lower in males than in females. MNA-SF total score $(\mathrm{p}=0.004)$ was significantly higher in males than in females. There was no significant relationship between MNA total score $(\mathrm{p}=0.299)$ and gender.

The mean of weight, height, arm and calf circumference, BMI and abdominal skin thickness was significantly higher in normal nutritional level than in those with malnutrition and those at risk of malnutrition $(\mathrm{p}<0.05)$, according to MNA-SF, except the thickness of the triceps skin $(\mathrm{p}=0.332)$. The comparison of nutritional level and anthropometric measurements according to MNA-SF is shown in Table V.

Table V. Comparison of nutritional status and anthropometric measurements according to MNA-SF

\begin{tabular}{|c|c|c|c|c|c|}
\hline Parameters & $\begin{array}{l}\text { Malnutrition } \\
\text { (a) }\end{array}$ & $\begin{array}{c}\text { Risk of } \\
\text { Malnutrition } \\
\text { (b) }\end{array}$ & $\begin{array}{l}\text { Normal } \\
\text { nutrition } \\
\text { (c) }\end{array}$ & & \\
\hline & Mean \pm SD & Mean \pm SD & Mean \pm SD & $\mathrm{F}$ & $\mathrm{p}^{*}$ \\
\hline Weight (kg) & $63.2 \pm 15.1$ & $69.1 \pm 15.4$ & $78.8 \pm 12.9$ & 13.951 & $\begin{array}{l}0.027^{\mathrm{ab}} \\
0.001^{\mathrm{ac}}\end{array}$ \\
\hline Height $(\mathrm{cm})$ & $161.1 \pm 9.5$ & $157.2 \pm 9.1$ & $163.2 \pm 9.9$ & 7.421 & $0.001^{\mathrm{bc}}$ \\
\hline $\begin{array}{l}\text { Arm } \\
\text { circumference } \\
(\mathrm{cm})\end{array}$ & $22.8 \pm 2.8$ & $25.3 \pm 3.2$ & $27.2 \pm 2.9$ & 14.279 & $\begin{array}{c}<0.001^{\text {bc }} \\
0.001^{\text {ac }}\end{array}$ \\
\hline $\begin{array}{l}\text { Calf } \\
\text { circumference } \\
(\mathrm{cm}) \\
\end{array}$ & $30.3 \pm 3.8$ & $32.8 \pm 4.3$ & $34.5 \pm 3.8$ & 6.880 & $\begin{array}{l}0.017^{a c} \\
0.023^{b c}\end{array}$ \\
\hline $\begin{array}{l}\text { Triceps skin } \\
\text { thickness } \\
(\mathrm{mm})\end{array}$ & $14.4 \pm 6.9$ & $18.9 \pm 8.7$ & $18.5 \pm 7.3$ & 1.108 & 0.332 \\
\hline $\begin{array}{l}\text { Abdominal } \\
\text { skin thickness } \\
(\mathrm{mm})\end{array}$ & $16.8 \pm 10.4$ & $24.3 \pm 7.8$ & $26.7 \pm 6.8$ & 8.243 & $\begin{array}{l}0.027^{\mathrm{ab}} \\
0.001^{\mathrm{ac}}\end{array}$ \\
\hline BMI $\left(\mathbf{k g} / \mathbf{m}^{2}\right)$ & $24.4 \pm 5.7$ & $28.0 \pm 6.2$ & $29.6 \pm 4.8$ & 5.287 & $0.020^{\text {ac }}$ \\
\hline
\end{tabular}

${ }^{*}$ BMI: Body mass index. $p^{*}=$ One-Way ANOVA test and Post Hoc tests were used

There was a moderate strong relationship in negative direction, between MNA-SF and GDS-30 ( $\mathrm{r}=-0.465, \mathbf{p}<\mathbf{0 . 0 0 1}$ and in positive direction, moderate strong relationship between MNA and SMMT $(\mathrm{r}=0.415, \mathrm{p}=0.002)$. Also a moderate negative relationship was found between MNA and GDS-30 ( $r=-0.393$, $\mathrm{p}=0.003$ ) and a high positive correlation between MNA and MNA-SF was noted $(r=0.809, \mathbf{p}<\mathbf{0 . 0 0 1})$. The correlation of age and geriatric assessment tests of the participants is shown in Table VI.

According to linear regression $21.7 \%$ of the decrease in MNA-SF total score was attributed to the total score of GDS-30 $\left(R^{2}=0.217\right.$, $\mathrm{p}<0.001)$. The linear regression analysis between the GDS-30 total score and MNA-SF is shown in Figure 1.
Table VI. Correlation of age and geriatric assessment tests of the participants

\begin{tabular}{|c|c|c|c|c|c|c|}
\hline Parameters & & Age & SMMT & GDS-30 & MNA-SF & MNA \\
\hline \multirow[t]{2}{*}{ Age } & $\mathrm{r}$ & \multirow[t]{2}{*}{1} & & & & \\
\hline & $\mathrm{p}$ & & & & & \\
\hline \multirow[t]{2}{*}{ SMMT } & $\mathrm{r}$ & $-0.285^{\star}$ & \multirow[t]{2}{*}{1} & & & \\
\hline & $\mathrm{p}$ & 0.000 & & & & \\
\hline \multirow[t]{2}{*}{ GDS-30 } & $\mathrm{r}$ & 0.018 & $-0.277^{\star}$ & \multirow[t]{2}{*}{1} & & \\
\hline & $\mathrm{p}$ & 0.758 & 0.000 & & & \\
\hline \multirow[t]{2}{*}{ MNA-SF } & $\mathrm{r}$ & $-0.219^{*}$ & $0.283^{*}$ & $-0.465^{*}$ & \multirow[t]{2}{*}{1} & \\
\hline & $\mathrm{p}$ & 0.000 & 0.000 & 0.000 & & \\
\hline \multirow[t]{2}{*}{ MNA } & $\mathrm{r}$ & -0.128 & $0.415^{*}$ & $-0.393^{*}$ & $0.809^{*}$ & \multirow[t]{2}{*}{1} \\
\hline & $\mathrm{p}$ & 0.356 & 0.002 & 0.003 & 0.000 & \\
\hline
\end{tabular}

SMMT: Standardized Mini Mental Test, GDS - 30: Geriatric Depression Scale Long Form, MNA: Mini-Nutritional Assessment Test, MNA-SF: Mini-Nutritional Assessment Short Form. ${ }^{\star}$ Correlation is significant at 0.01 level

\section{GERIATRIC DEPRESSION TOTAL SCORE}

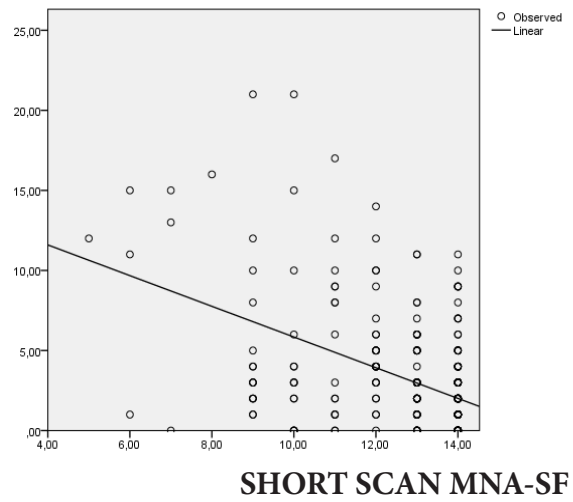

$\mathrm{R}^{2}=\mathbf{0 . 2 1 7 ,} \quad \mathrm{p}<0.001$

$\mathrm{R}^{2}=$ Regression coefficient of determination

Figure 1. Linear regression analysis between GDS-30 total score and MNA-SF

GDS-30: Geriatric Depression Scale (Long Form)

MNA-SF: Mini-Nutritional Assessment (Short Form)

\section{DISCUSSION}

Due to the increase in the elderly population in Turkey and in the world, there is a significant increase in the prevalence of chronic diseases and malignancies besides a decrease in cognitive abilities. In this study, the prevalence of dementia was found as $11.4 \%$. In a study conducted by Ertekin et al., the prevalence of dementia was found to be $6.4 \%$ [16]. Another study conducted in Elazig noted the prevalence of dementia as $5.9 \%$ in males, $9 \%$ in females and $7.3 \%$ on average [17]. Scazufca et al., reported the prevalence of dementia as $5.1 \%$ in those over 65 years of age in the 2072 study group. In the same study, the prevalence of dementia was found to be $21.4 \%$ in participants over 85 years of age [18]. We think that this difference is due to different sociodemographic characteristics such as education, sociocultural level and living standards. 
The prevalence of depression was 5.7\% in this study. Cankurtaran et al., found the prevalence of depression as $21.8 \%$ in 1255 elderly consisting of 789 women and 466 men [19]. Hustey and Smith studied 267 people over 70 years of age in the USA and the prevalence of depression was $16.5 \%$ in their study [20]. Sahin and Yalcin reported the prevalence of depression as 37.2 $\%$ for those living in their own homes and $48.1 \%$ for those living in nursing homes in individuals aged 65 and over in Edirne [21]. Comparing to the literature, the depression risk seems to be lower in the study we reported. This difference may be due to the cultural effect like family structure and partly may be due to the higher number of men in this study.

Malnutrition risk was $15.8 \%$, and $2.3 \%$ of the study group had malnutrition. In the study performed on elderly patients admitted to the internal medicine geriatrics outpatient clinic of Hacettepe University, $32.2 \%$ of the 236 patients were at risk of malnutrition and $19.5 \%$ had malnutrition [12]. In another study, it was found that $26.5 \%$ of males over 65 years were at risk of malnutrition and $0.9 \%$ had malnutrition [22]. The risk of malnutrition was lower in this study and this may be attributed to the research area. In the primary health care centers it was supposed to be lower than in a university hospital.

One step further MNA showed that $14.4 \%$ of the participants were at risk of malnutrition and one percent of them had malnutrition. In the study conducted at Istanbul University, the prevalence of malnutrition risk was $31 \%$ and malnutrition was $13 \%$ in patients who applied to the geriatrics outpatient clinic; malnutrition risk was $39 \%$ and malnutrition was $25 \%$ in patients who stayed in hospital [23]. The prevalence of malnutrition was found to be $12.2 \%$ in Iranian elderly over 60 years of age with MNA test and this rate was $21.6 \%$ in elderly in nursing homes [24]. In the assessments performed by MNA test in Taiwan in individuals aged 65 and over, the prevalence of malnutrition was $1.7 \%$ for males, $2.4 \%$ for females and the prevalence malnutrition risk was $13.1 \%$ [25]. Again this study became different, with a lower prevalence of malnutrition and primary health care and university specific units in geriatrics may be the reason for this difference.

This study showed that there was more cognitive impairment in women than in men. Similarly, in a study conducted in China, the prevalence of cognitive impairment was found to be higher in women than in men [26]. Kutlu et al., noted similar results also [27]. Although, there was no relationship between dementia and education in male gender, dementia was less common in educated women according to the study we reported. Due to the high level of education in men, it was thought that the difference in cognitive function in women may be related to education level.

The presence of dementia was found to be more in those aged 75 years and over as expected because advanced age was a risk factor for cognitive impairment. In another study, the prevalence of dementia also increased in correlation with age, while it was found as 3\% between the ages of 65-74 and it was found as $50 \%$ in people aged 85 and over [28]. As in previous studies, according to the increase in the prevalence of dementia according to age groups in this study, it may be claimed again that age is a risk factor for dementia.

A significant relationship was found between the decrease in education level and SMMT deterioration. According to education level, $24.1 \%$ of illiterate people had dementia, but for primary school and upper educational level, this rate was $6.8 \%$. In a metaanalysis authors noted that 51 studies (58\%) reported significant effects of low education on dementia risk, while 37 studies (42\%) reported no significant relationship [29]. It can be considered that education level is a reflection of socioeconomic level and higher education reduces the risk of dementia due to better living conditions and less environmental factors.

The prevalence of dementia was higher in participants with malnutrition and in those at risk of malnutrition than in those with normal nutrition. Consistent with the literature, SMMT scores were also lower in patients who had low scores according to MNA and MNA-SF [23]. People with cognitive decline are known to have various eating and swallowing problems. Behavioral and psychological symptoms of dementia, as well as eating and swallowing problems, can strongly influence nutritional status.

Dementia was found in nearly half of the patients with depression, while it was found to be lower in patients without depression. The literature also says that depression is an important risk factor for dementia [19]. The mean score of SMMT was higher in men than women. Similar results have been reported in two studies [30]. The higher total SMMT score in males may be due to the higher level of education in them as mentioned above.

\section{Limitations}

Although, the subject of our study was extensive and important, we had to keep our working group small because of the economic factors. The fact that this study was not planned in larger groups as a multi-center study shows our limitation. Although, the results of the study cannot be reflected in the general public, we believe that it will be a study that contributes to the literature and can contribute to future studies with its important results about the role of family physicians in primary care.

\section{Conclusion}

In this study, the prevalence of dementia, depression, malnutrition and malnutrition risk was $11.4 \%, 5.7 \%, 1 \%$, and $14.4 \%$, respectively. The presented study showed a higher prevalence of dementia specifically in lower educated women, in more depressive women, in women who had malnutrition and in individuals aged 75 years over. Priority should be given to the training of physicians providing primary health care services so that they can recognize the symptoms of dementia, depression and malnutrition. They should be taught how to make a differential diagnosis and when to make a consultation and when to make a referral to specific health care. Regarding dementia, depression and malnutrition in the elderly in primary care; it is important to use well - designed specific scales for these conditions for early diagnosis. It will affect the quality of life of the elderly and their care givers. 


\section{Compliance with Ethical Standards}

Ethical approval: Ethics committee approval was received before starting the study (Number: 2017/1054 Date:03.11.2017). The participants were informed about the study and their written and verbal consent was obtained according to the principles of Helsinki Declaration.

Financial support: The authors have no relevant financial information to disclose.

Conflict of interest: The authors have no potential conflicts to declare.

Authors' contributions: Study conception: ST and RK, Design: RK, ST, Supervision: RK and NK, Data collection: ST, Formal analysis and investigation: RK and NK, Resources: ST, Writingreview and editing: RK, ST and NK. All authors approved the final version of the article.

\section{REFERENCES}

[1] Prince M, Bryce R, Albanese E, Wimo A, Ribeiro W, Ferri CP. The global prevalence of dementia: A systematic review and metaanalysis. Alzheimers Dement 2013;9:63-75.e2. doi: 10.1016/j.jalz.2012.11.007.

[2] WHO Expert Committee. Health of Elderly. Geneva: World Health Organization, 1989. Technical Report Series 779. http://whqlibdoc.who.int/trs/WHO_TRS_779.pdf. Access date: 05.01.2019.

[3] Elderly with Statistics, 2017. Turkey Statistical Institute (TSI). www.tuik.gov.tr/PreHaberBultenleri.sayı:27595. Access date: 10.09.2018.

[4] Ahmed T, Haboubi N. Assessment and management of nutrition in older people and its importance to health. Clin Interv Aging 2010;5:207-16. doi: 10.2147/cia.s9664.

[5] Gürvit H, Bilgiç B. The concept of dementia, developmental and acquired disorders of dementia. Emre M, ed. Neurology Basic Book. First Edition, Ankara: Güneş Medical Bookstores, 2013;936-938 (In Turkish)

[6] Arslantas D, Ozbabalik D, Metintas S, et al. Prevalence of dementia and associated risk factors in Middle Anatolia, Turkey. J Clin Neurosci 2009;16:1455-9. doi: 10.1016/j. jocn.2009.03.033. Epub 2009 Sep 11.

[7] Sozeri-Varma G. Depression in the elderly: Clinical features and risk factors. Aging Dis 2012;3:465-471.

[8] Folstein MF, Folstein JE, McHugh PR. "Mini Mental State" a practical method for grading the cognitive state of patients for the clinician. J Psychiatr Res 1975;12:189-98. doi: 10.1016/0022-3956(75)90026-6.

[9] Gungen C, Ertan T, Eker E, Yasar R, Engin F. Reliability and validity of the standardized mini mental state examination in the diagnosis of mild dementia in turkish population. Turkish Journal of Psychiatry 2002;13:273-281.

[10] Vellas B, Villars H, Abellan G, et al. Overview of the MNA-Its history and challenges. J Nutr Health Aging 2006;10:456-63.

[11] Rubenstein LZ, Harker JO, Salva A, Guigoz Y, Vellas B. Screening for undernutrition in geriatric practice: developing the short-form mini-nutritional assessment (MNA-SF). J Gerontol A Biol Sci Med Sci 2001;56:M366-72. doi: 10.1093/ gerona/56.6.m366.

[12] Sarikaya D, Halil M, Kuyumcu ME, et al. Mini nutritional assessment test long and short form are valid screening tools in Turkish older adults. Arch Gerontol Geriatr 2015;61:56-60. doi: 10.1016/j.archger.2015.04.006.

[13] Arığul S (ed). Yaşlılarda malnütrisyon kılavuzu. Ankara: Akademik Geriatri Derneği, 2013.

[14] Yesavage JA, Brink TL, Rose TL, et al. Development and validation of a geriatric depression screening scale: a preliminary report. J Psychiatr Res 1982-1983;17:37-49. doi: 10.1016/0022-3956(82)90033-4.

[15] Ertan T, Eker E, Sar V. Validity and reliability of geriatric depression scale in Turkish elderly population. Nöropsikiyatri Arşivi 1997;34:62-71.

[16] Ertekin A, Özdemir G, Özel L, Özyıldırım E, Ulvi H. An investigation of the risk factors and prevalence of Alzheimer's disease in the eastern region of Turkey. Eur J Gen Med 2015;12:144-51. doi.org/10.15197/sabad.1.12.29

[17] Bulut S, Ekici I, Polat A, et al. Prevalence of dementia and dementia subgroups in Abdullahpaşa region of Elazığ province. Journal of Dementia 2002; 2:105-110. (Article in Turkish)

[18] Scazufca M, Menezes PR, Vallada HP, et al. High prevalence of dementia among older adults from poor socioeconomic backgrounds in Sao Paulo, Brazil. Int Psychogeriatr 2008;20:394-405. doi: 10.1017/S104.161.0207005625.

[19] Cankurtaran M, Halil M, Yavuz BB, Dagli N, Ariogul S. Depression and concomitant diseases in a Turkish geriatric outpatient setting. Arch Gerontol Geriatr 2005;40(3):307-15. doi: 10.1016/j.archger.2004.10.002.

[20] Hustey FM, Smith MD. A depression screen and intervention for older ED Patients. Am J Emerg Med 2007;25:133-7. doi: 10.1016/j.ajem.2006.05.016.

[21] Sahin EM, Yalcin BM. Comparing the incidences of depression at the elderly living in nursing home or at their own homes. Turkish Journal of Geriatrics 2003;6:10-3.

[22] Montejano Lozoya R, Martínez-Alzamora N, Clemente Marín G, Guirao-Goris SJA, Ferrer-Diego RM. Predictive ability of the Mini Nutritional Assessment Short Form (MNA-SF) in a free-living elderly population: a cross-sectional study. Peer J 2017;5:e3345. doi: 10.7717/peerj.3345. eCollection 2017.

[23] Saka B, Kaya O, Ozturk GB, Erten N, Karan MA. Malnutrition in the elderly and its relationship with other geriatric syndromes. Clin Nutr 2010;29:745-8. doi: 10.1016/j. clnu.2010.04.006. Epub 2010 Jun 2.

[24] Gorji HA, Alikhani M, Mohseni M, Moradi-Joo M, Ziaiifar H, Moosavi A. The prevalence of malnutrition in Iranian Elderly: A review article. Iran J Public Health 2017;46:1603-10.

[25] Tsai AC, Ho CS, Chang MC. Assessing the prevalence of malnutrition with the Mini Nutritional Assessment (MNA) in a nationally representative sample of elderly Taiwanese. J Nutr Health Aging. 2008;12:239-43. doi: 10.1007/BF02982628.

[26] Hai S, Cao L, Yang X, et al. Association between nutrition status and cognitive impairment among Chinese nonagenarians 
and centenarians. International Journal of Gerontology 2017;17(4):215-19. doi.org/10.1016/j.ijge.2016.12.002

[27] Kutlu R, Karaoglu N, Marakoglu K, Civi S. Evaluation of the mini-mental state examination among the elderly people in Konya, Turkey. Neurosciences (Riyadh). 2006;11:297-301.

[28] Castellani R, Rolston RK, Smith MA. Alzheimer disease. Dis Mon 2010;56: 484-546. doi: 10.1016/j.disamonth.2010.06.001.
[29] Sharp ES, Gatz M. Relationship between education and dementia: an updated systematic review. Alzheimer Dis Assoc Disord 2011;25:289-304. doi:10.1097/WAD.0b013e318211c83c.

[30] Zhang Y, Shi Z, Liu M, et al. Prevalence of cognitive impairment no dementia in a rural area of Northern China. Neuroepidemiology 2014;42:197-203. doi: $10.1159 / 000360138$. 